\title{
VIRTUAL ENTERPRISE BROKER: PROCESSES, METHODS AND TOOLS
}

\author{
Ricardo Mejía, Arturo Molina \\ CSIM-ITESM \\ Ave. Eugenio Garza Sada 2501 Sur \\ Monterrey, N.L. 64849 MEXICO
}

(52) 8-358-2000 Ext.5109 \& 5186, fax: (52) 8-328-41-23

rmejia@tamayo.mty.itesm.mx, armolina@campus.mty.itesm.mx

\begin{abstract}
The role of the broker in nowadays e-business is getting special attention. This paper presents a description of an e-broker, named Virtual Enterprise Broker (VEB). The core processes, methods and tools used by the VEB in order to fulfill the customer's requirements are described. The four core processes of the VEB are: Analysis of Market Requirements, Project Planning, Project execution and Customer Service. All of these core processes requires the use of different methods and tools. Three proposed information systems to suppon the VEB activities are presented: Enterprise Core Competence Database, Enterprise Capability Broker Matrix and Broker Capacity Planning Tool. Finally, experiences in creating Integrated Supply Chains between SME, members of Virtual Industry Clusters, to OEMs (Original Equipment Manufacturers) in the Mexican Industry will be presented as case studies to demonstrate the use of the methods and tools presented in this paper.
\end{abstract}

\section{INTRODUCTION}

The cooperation of six universities through the COSME network developed a framework for Global Virtual Business to better understand how Virtual Enterprises work [5]. The framework is composed by three main business entities: Virtual Industry Clusters (VICs), Virtual Enterprise Broker (VEB) and Virtual Enterprise (VE). Each one of these business entities has been defined as follows [3]:

1. Virtual Industry Cluster (VIC): Aggregation of companies from diverse industries, with well defined and focused competencies, with the purpose of gaining access to new markets and business opportunities by leveraging their resources.

2. Virtual Enterprise Broker (VEB): This business entity is responsible for searching opportunities in the global environment and enables the creation of Virtual Enterprises. The Virtual Enterprise Broker performs the 
processes of partner search and partner selection, and configures suitable infrastructures for VE formation/commitment (physical, legal, social/cultural, information). To achieve its goal the VEB uses the services provided by Virtual Industry Clusters.

3. Virtual Enterprises (VE): Temporary networks of independent companies linked by information technology that share competencies, infrastructure and business processes, with the purpose to fulfill a specific market requirement.

A Virtual Enterprise Broker and Virtual Industry Clusters form a Virtual Organization, and can be defined as an organization form in which a collection of legally independent enterprises, institutions, or single persons come together to cooperate for a particular mission. Each member brings to the cooperation its core competencies relevant to a mission.

The main objective of a Virtual Organization is to create Virtual Enterprises to exploit business opportunities identified by the Virtual Enterprise Broker using core competencies deployed from partners from different Virtual Industry Clusters. The role of the Broker in Virtual Enterprise is much more than just the identification of market needs. The VEB is in charge of identifying, selecting and qualifying best partners for the Virtual Enterprise. Also the responsibility will be to manage the partner's competencies. In order to exploit the global business opportunities successfully and to satisfy the customer's requirements in the Global Business Environment, new tools and methods must support the brokerage activities. Research related to the broker role in Virtual Enterprises is still in its infancy. However the focus of the research nowadays has been in providing information tools to support brokerage activities [1]. In this paper a description of practical experiences of how to operate a Virtual Enterprise Broker (VEB) is presented in terms of: processes, methods and tools.

\section{VIRTUAL ENTERPRISE BROKER CORE PROCESS}

The Virtual Enterprise Broker (VEB) is looking for new opportunities to satisfy market's needs through the formation of Virtual Enterprises. Additionally, the VEB must be able to organize the competencies of the companies in order to carry out new business projects. All of the tasks carried out by the VEB requires the use of the information regarding possible companies around the world, that can be in Virtual Industry Clusters or elsewhere, which have to be selected, organized, and integrated to satisfy user requirements for a product, a manufacturing process or access to a technology. In this research four core processes have been defined for the VEB: Analysis of Market Requirements, Project Planning, Project Execution and Customer Service (figure 1). 


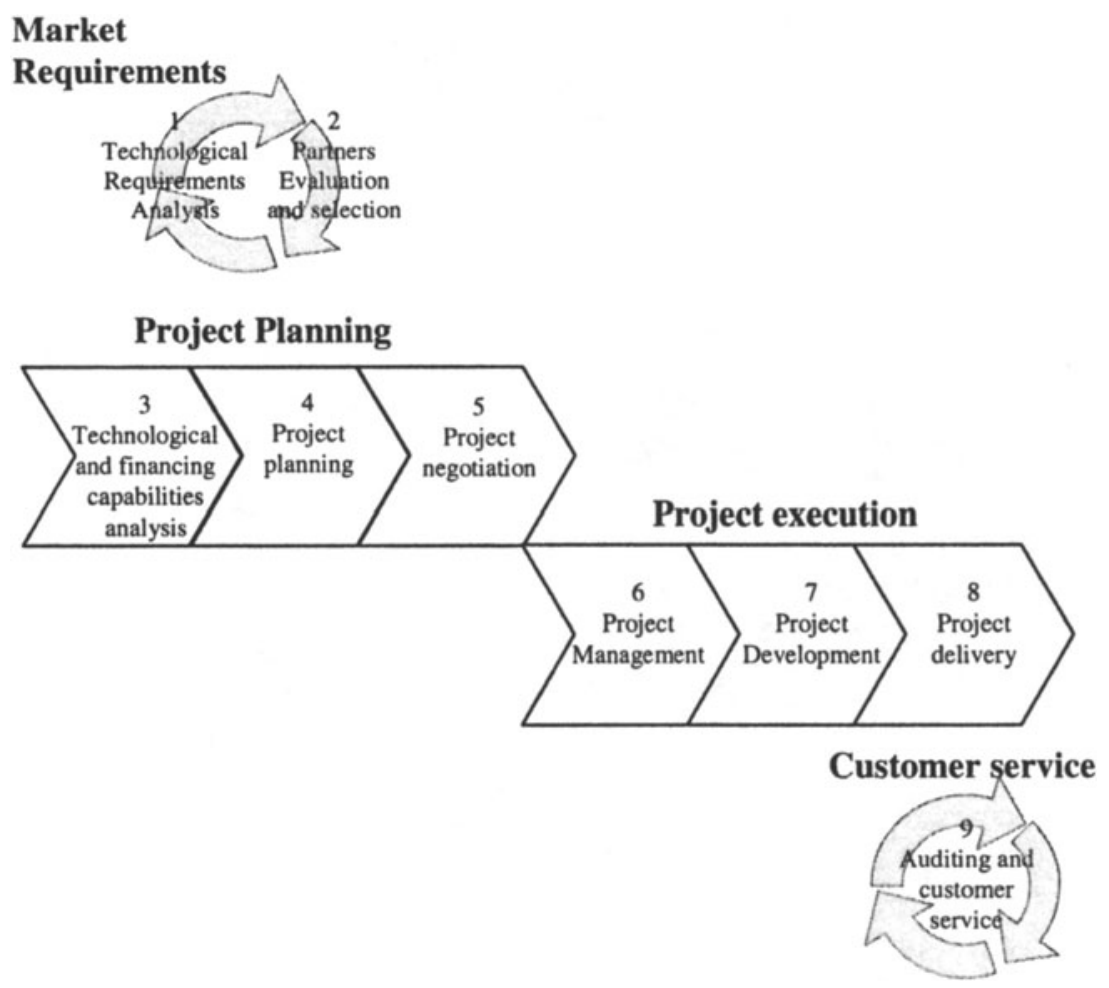

Figure 1 - Virtual Enterprise Broker core process

Three major services can be carried out by the VEB (figure 2): Integrated Product Development, Services for Integration Engineering and Constructions Systems, and Technology Development and Commercialization.

Integrated Product Development is related to the transfer of a product or a technology from an OEM to a major supplier or the development of new products conceived by an OEM. Integration Engineering and Construction Systems services have to do with identifying specific market requirements for a process or technology, and matching it with the company or companies that has access to such a process or technology. Finally, technology development and commercialization focused in identifying pacing technologies that can rapidly be incorporated into new products to create new markets niches. The incorporation and integration of the right companies to achieve this latter approach is key for the successful commercialization of a technology.

\subsection{Market Requirements Analysis}

The first process of the VEB is key in the identification of business opportunities. The first task is the "Technological Requirements Analysis" where 
the VEB must be constantly looking for requirements from industry in order to find potential business deals. This activity is supported with methods such as competitive intelligence analysis by determining, for example, emerging economical sectors in a specific country. With this analysis the VEB can define targeted markets or industries. A service that the VEB can perform is the analysis of customer's products to carry out a cost-benefit trade-off to verify if a strategic outsourcing is possible.
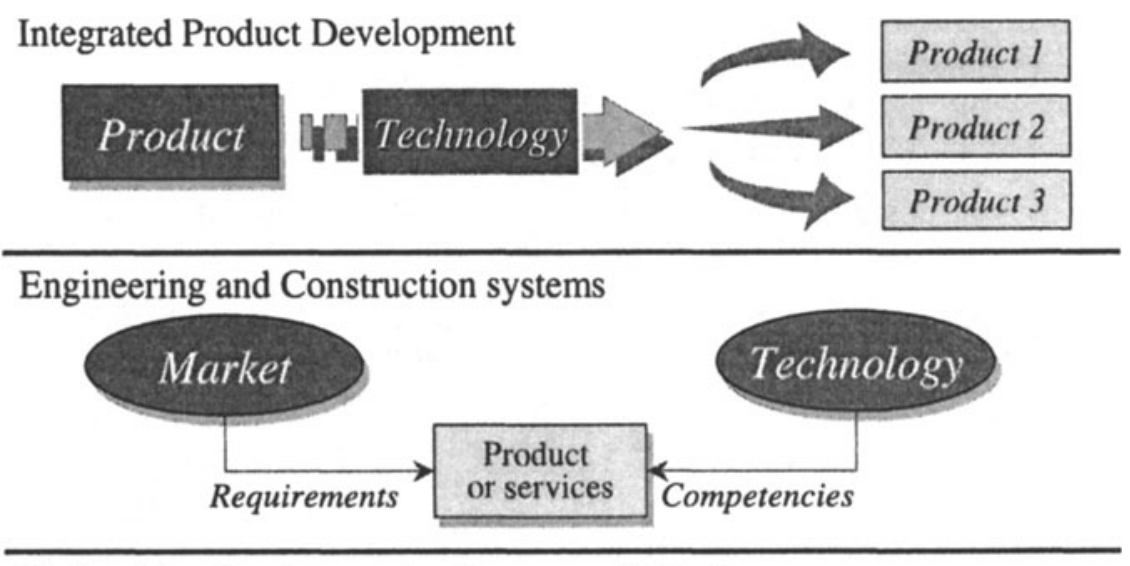

Technology development and commercialization

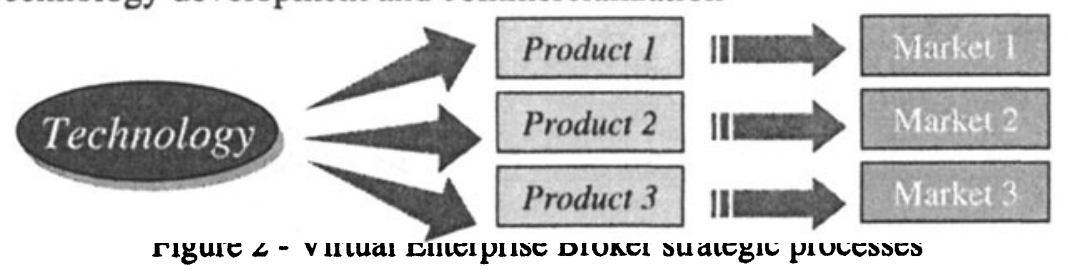

The next task "Partners evaluation and selection" begins when a potential business opportunity is found. Here, the next step is the analysis and selection of the potential partners to configure the Virtual Enterprise. In this stage, the VEB must determine the competencies needed to satisfy the requirements demanded by the industry. The VEB has to select, analyze and configure the competencies in order to create a Virtual Enterprise able to carry out the project.

\subsection{Project Planning}

Once the needs of the market are known and the potential partners to configure the Virtual Enterprise are selected, a business project has to be planned. The most important activity to be performed is the technological and financial capability analysis of the Virtual Enterprise (VE) in order to prepare a business plan for the VE. Here it is important to evaluate the technical and financial possibilities of the 
companies selected, and also to foresee the possible value added of the VE. If the results of the analysis are satisfactory, then a negotiation takes place between the customer and the VE, in all the cases there should be a responsible for representing the VE. In our case, a company in the VE takes this responsibility, however when no company wants to assume this risk, the VEB must act accordingly and take responsibility.

\subsection{Project Execution}

At this stage, the VEB manages the project execution of the VE. Different activities take place related to project management. However the key activity in this core process is project development. There are different kinds of projects that can be carried out by the VE using the concept of an Integrated Product Development. The Integrated Product Development carried out by the VEB to create new products using the core competencies of the companies in the Virtual Industry Cluster (VIC) is related to four main activities: Ideation, Basic Development, Advanced Development and Launching. At different stages a set of methods are required to support the VEB activities among them: QFD, Triz, FMEA, and DFx. The use of these tools assures customer's requirements to be satisfied. Detail explanation of these methods can be found in [7]. Depending on the kind of market needs, the different types of projects are: Product transfer, Technology transfer and New Product Development.

\section{Project execution stage}

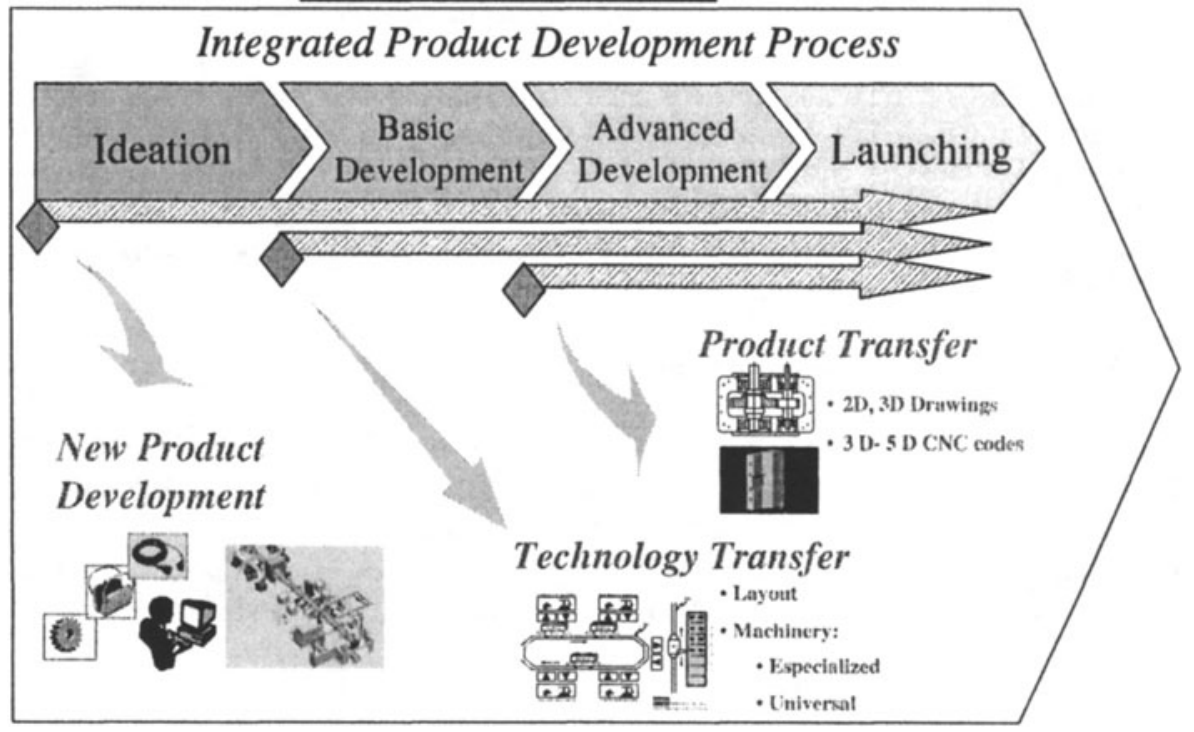

Figure 3 - Classification of the business opportunities in the Integrated Product Development process 


\subsubsection{Product transfer}

This case is very common in the Maquiladora Industry (Maquiladora is an international manufacturing company established in Mexico with special taxes agreements). It consists of the transfer of products from the Maquiladora (sometime an OEM) to the potential supplier, in our case the Virtual Enterprise. This kind of transfer fits in the Integrated Product Development stages at the Advanced Development, because the VE does not design the product, just design the manufacturing process, and distributes the capacity (volume) among the different companies in the VE. This is a very straightforward process, where the major concern from the customer is that the VE should meet with the quality, time and volume.

\subsubsection{Technology transfer}

This second case, technology transfer, can be better described with an example. A company wants to outsource most of their products and/or process. This practice is common when an OEM wants to carry out just the final assembly process, therefore an analysis of the part/components of their products have to be performed. Once the analysis is complete, decisions have to be made regarding which part/components can be outsourced. Sometimes, in order to keep the quality of the product, a technology transfer have to be carry out in order that the supplier can run the manufacturing process, therefore the OEM will transfer the product and the manufacturing facility to manufacture the product to the potential supplier.

In this case the VEB analyzes the parts and components of the products and with this information and with the VIC information, a configuration of a Virtual Enterprises or selection of a single company can be carried out. This kind of transfer from OEM to SME can be located at the Basic Development, because the product is defined, but there are still activities to be developed regarding the product and facility to manufacture the product.

\subsubsection{New Product Development}

When the customer needs a new product, almost all the stages of the Integrated Product Development are carried out. Usually the customer transfer "concepts of a product" to the suppliers, then a supplier have to perform the Basic Development definition of a product and all the following phases. Another example, is when the supplier proposes changes to a design or when the OEM needs a relative new product.

Additionally the VEB can conceive a new product, then a VE is required to image, design and manufacture new products to be launched to the market and in that case the execution of all stages must be done, starting in the Ideation stage. 


\subsection{Customer Service}

The last process is the following up of the projects carried out by Virtual Enterprises. The VEB must be constantly checking the projects agreements and also give the necessary support to the correct working of the Virtual Enterprises in order to give a better service and customer needs fulfillment. Here the tasks required by the client are constantly checked and follow up.

\section{VIRTUAL ENTERPRISE BROKER METHODS}

A set of methods and techniques are proposed to support the VEB activities in order to improve the VEB core process and to assure the correct operation of the Virtual Enterprise.

Companies used by the VEB to configure a Virtual Enterprise, must be evaluated in order to fulfill the competencies required to design and fabricate a product. One of the most important methods for partner selection is the IMMPAC @ Methodology [4]. The companies from Virtual Industry Clusters are evaluated from three different stages: Stage 1 - Competitive Assessment, Stage 2 - Productivity Indicators Evaluation, Stage 3 - Best Practices Evaluation and finally a Enterprise Development Plan is giving to the companies to meet VE requirements. Based on this evaluation the VEB know the companies and can select correctly those whose competencies are the needed to exploit a new business opportunity. Some of the main methods used by the VEB are described in Table 1.

Table 1 - Virtual Enterprise Methods and Tools.

\begin{tabular}{|c|c|c|}
\hline Process stage & Methods & Tools \\
\hline $\begin{array}{l}\text { Market } \\
\text { Requirements }\end{array}$ & $\begin{array}{l}\text { - Competitive Intelligence } \\
\text { analysis } \\
\text { - IMMPAC }\end{array}$ & $\begin{array}{l}\text { - Internet } \\
\text { - Databases } \\
\text { - CRM }\end{array}$ \\
\hline Project Planning & $\begin{array}{l}\text { - Business Plan Techniques } \\
\text { - Capability and capacity } \\
\text { analysis } \\
\text { - IDEF0 }\end{array}$ & $\begin{array}{l}\text { - Project management } \\
\text { - Worksheets } \\
\text { - Workgroup and } \\
\text { Groupware } \\
\end{array}$ \\
\hline Project execution & $\begin{array}{l}\text { - } \text { QFD } \\
\text { - Triz } \\
\text { - FMEA } \\
\text { - } \text { DFx }\end{array}$ & $\begin{array}{l}\text { - Project management } \\
\text { - Applications to support } \\
\text { specialized activities: } \\
\text {-CAD/CAM/CAE } \\
\text {-ICAD } \\
\end{array}$ \\
\hline Customer Service & $\begin{array}{l}\text { - Control Graphs } \\
\text { - Check list }\end{array}$ & $\begin{array}{l}\text { - Statistical Software } \\
\text { - Internet }\end{array}$ \\
\hline
\end{tabular}




\section{VIRTUAL ENTERPRISE BROKER TOOLS: INFORMATION TECHNOLOGIES FOR VIRTUAL ENTERPRISES}

Three proposed information systems to support the VEB activities are presented: Enterprise Core Competence Database, Enterprise Capability Broker Matrix and Broker Capacity Planning Tool.

The Web-based Enterprise Core Competence Database, named Manufacturing Model, was implemented with the idea of supporting selection of suppliers in Virtual Enterprise. The prototype system allows capturing manufacturing information related to resources, processes and strategies of a company. The information about a factory can be capture at different levels within the organization, for example Factory, Shop floor, Cell and Station. This is important because the model also supports the organization of this information for the companies in the database [6]. Figure 4 shows the interface for data entry in the Manufacturing Model.

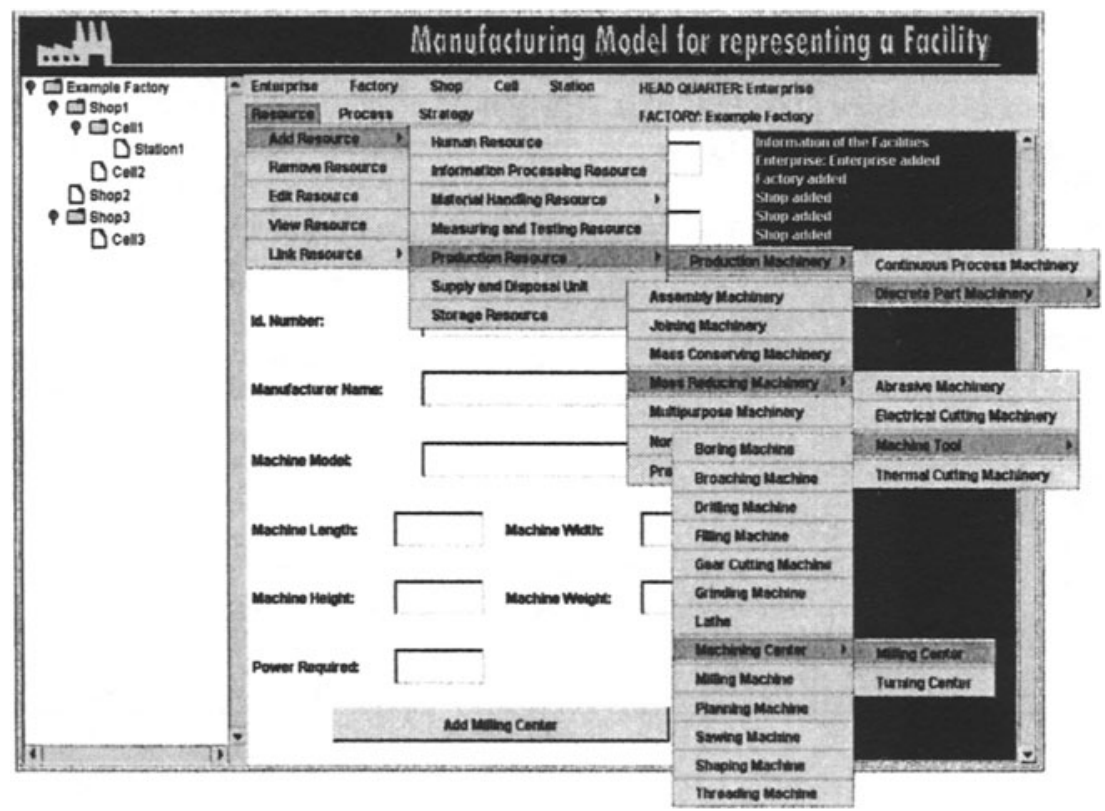

Figure 4 - Manufacturing Model data entry interface

Queries can be performed to find machines and processes in the database; also companies that are capable of performing a process o have a specific resource. Sometimes the search for suppliers in a Virtual Enterprise requires to query in specific clusters, for example all companies that can process plastics or are die and mould makers, and so on. The Manufacturing model is a Web-based system based on the use of Internet and object oriented database technologies. The system was 
developed with Java and use Object Store OODBMS in order to provide efficient retrieval of the data and management of the complex data model. The databases reside on a Sun Ultra 5 Server which works as a Web Server. The interfaces to access the Manufacturing Model prototype systems were developed with Java applets and can be accessed through any common browser, i.e. Netscape or Explorer. The prototype is running in the CSIM-ITESM project called Mexican Industry (www.mexican-industry.com.mx) for companies searching based on

Two other tools are under development: Enterprise Capability Broker Matrix and Broker Capacity Planning Tools. The first tool supports the VEB in evaluating and selecting the right partners to satisfy a business opportunity. Information from different potential partners can be analyzed and compared. Combination of competence based on cost criteria can be evaluated.

The Broker Capacity Planning Tool is being design as an addition to the Manufacturing Model application, where information related to the actual capacity of a member of the Virtual Industry Cluster can be captured on-line. Therefore the VEB can know if a company is available to participate in a VE or not, due to their restrictions of available capacity to deliver the needed volume on time. The idea is to fill the information through the Internet, to know the real time capacities from the clusters Members in order to feed a simulation tool that can be able to determine the weekly VE throughput. Research related to Brokers tools can be found in [2].

\section{CASE STUDY}

Seven Virtual Industry Clusters have been created and are managed by the Integrated Manufacturing Systems Center (CSIM-ITESM) in Monterrey (www.mexican.industry.com). Experiences in the role of the VEB will be described with two cases from companies from the Virtual Industry Clusters.

The first case is a Product transfer that was detected by the VEB. The company had the need to replace an actual supplier because quality and lead times were no satisfied. The product was composed by seven components, and the OEM (Original Equipment Manufacturer) was able to provide four, but the critical parts was an injection molded component and an electrical transformer. In this case the VEB looked for SMEs (Small and Medium Enterprises), which be able to inject the part and also, perform the final assembly. In this case the VEB was in charge to find a supplier of the transformer, because no cluster company was able to manufacture it. In this case the VE was not created because while doing the business plan it was not possible to meet the price requirements set by the customer.

The second case is also a product transfer. The VEB contacted an OEM from the automotive industry, and the analysis showed the interest from the OEM to replace foreign supplier to local ones. The company, with the VEB, identified a potential component to be made by the VIC. The VEB looked for the companies with the manufacturing capacity to meet OEM requirement. The negotiation begins, an audition from the OEM to the SMEs was done and the prototype and quotation was 
accepted. In this case, only one company was able to manufacture the components, there was no need to build a VE.

Finally, the experience has shown that the OEMs are not very familiar with Virtual Enterprises, and actually the brokers are working as an intermediary entity just finding contacts to the Cluster members. In order to improve that, there has been a need to create a new formal enterprise that will be responsible for all the aspects of a customer need, and formalize the creation and execution of a VE. This new business has been named IECOS (Integration Engineering and Construction Systems) and has been created based on the concept of VEB (www.iecos.com.mx).

\section{CONCLUSIONS}

The business entity of the Virtual Enterprise Broker (VEB) has been described in terms of core processes, methods and tools. The core processes of the VEB have been defined to be: analysis of market requirements, project planning, project execution and customer service. Special attention has been made in the project execution where a VEB can tackle different types of business opportunities: product transfer, technology transfer and new product development. Different methods have been used to support the execution of these core processes, to name just a few: QFD, AMEF, DFX. Also computer tools have been designed and implemented, of special interest is the Manufacturing Model a web-based information model that captures the technological resources of a company, and can be used by the broker for company selection. Two real cases have been explaining of how a broker can undertake the role of doing business. There is still a lot of research to be done regarding the organization and operation of a VEB, this paper presents a first insight into the formalization of this role in a Virtual Business environment.

\section{REFERENCES}

[1] Camarinha-Matos L.M., Afsarmanesh H., Rabelo R. (Editors.), E-Business and Virtual Enterprises: Managing Business-to-Business Cooperation, Kluwer Academic Publishers, 2000

[2] Kanet J.J., Faisst W., Mertens P., "Application of Information technology to a virtual enterprise broker: the case of Bill Epstein", Int. J. Production Economics, 62 (1999), 23 - 32.

[3] Molina A., Ponguta S., Bremer C.F., Eversheim W., "Framework for Global Virtual Business", Agility \& Global Competition, Vol. 2, No. 3, 1998, pp. 56-69

[4] Molina A., Flores M., "Exploitation of Business Opportunities: the role of the Virtual Enterprise Broker", in E-Business and Virtual Enterprises: Managing Business-to-Business Cooperation, L.M. Camarinha-Matos, H. Afsarmanesh, Rabelo (Eds.), Kluwer Academic Publishers, 2000, pp. 269 280.

[5] Molina A., Bremer C., Eversheim W., "Achieving critical mass: a global research network in systems engineering", foresight, Vol. 3, No 1, February 2001

[6] Molina A., Acosta J.L., Al-Ashaab A., Rodriguez K., "Web-based information model to support product development in Virtual Enterprises", in Digital Enterprise Challenges - Life Cycle Approach to Management and Production, , George L. Kovács, Peter Bertók, Géza Haidegger, (Eds.), Kluwer Academic Publishers, 2001, pp. 284-295.

[7] Prasad D., Integrated Product and Process Organization, in: Concurrent Engineering Fundamentals, volume 1, Prentice Hall PTR, Englewood Cliffs, NJ, 1996. 